\title{
CULTIVARES DE MILHO AFETADAS PELA ÉPOCA DE SEMEADURA NA SAFRINHA EM TOCANTINS
}

\author{
RODRIGO VÉRAS DA COSTA ${ }^{1}$, JONES SIMON ${ }^{2}$, DAGMA DIONÍSIA DA SILVA ${ }^{1}$, \\ LUCIANO VIANA COTA ${ }^{1}$, RODRIGO ESTEVAN MUNHOZ DE ALMEIDA ${ }^{2}$ \\ e LEONARDO JOSÉ MOTTA CAMPOS ${ }^{3}$
}

\begin{abstract}
${ }^{1}$ Laboratório de Fitopatologia, Embrapa Milho e Sorgo, Rod MG 424, Km 65, Cx. Postal 151, 35701-970, Sete Lagoas-MG, Brasil. rodrigo.veras@embrapa.br,dagma.silva@embrapa.br,luciano.cota@embrapa.br.

${ }^{2}$ Embrapa Pesca e Aquicultura, Prolongamento da Avenida NS 10, cruzamento com a Avenida LO 18, sentido Norte, s/n - Loteamento Água Fria, Palmas - TO, 77008-900. jones.simon@embrapa.br, rodrigo.almeida@embrapa.br.

${ }^{3}$ Embrapa Soja, rodovia Carlos João Strass, s/n ${ }^{\circ}$ Acesso Orlando Amaral,

Distrito de Warta Caixa Postal: 231 CEP: 86001-970-Londrina-PR. leonardo.campos@embrapa.br.
\end{abstract}

Revista Brasileira de Milho e Sorgo, v.16, n.3, p. 469-480, 2017

\begin{abstract}
RESUMO - O estresse hídrico e a ocorrência de doenças foliares são os principais desafios para o cultivo do milho safrinha em Tocantins, que é realizado no final do período chuvoso. O presente trabalho teve como objetivo avaliar o efeito da época de semeadura e das doenças foliares no desempenho de cultivares de milho cultivado na safrinha em Tocantins. Foram avaliadas 11 cultivares nas safrinhas de 2014 e 2015. As semeaduras foram realizadas em 03/02/2014, 25/02/2014, 12/02/2015 e 12/03/2015. Foi utilizado o delineamento experimental de blocos ao acaso, em arranjo fatorial 11x2 (cultivares x épocas de semeadura). Foram observadas diferenças para os fatores cultivares e épocas de semeadura para todas as variáveis estudadas. $\mathrm{O}$ atraso na época de semeadura reduziu drasticamente a produtividade da cultura do milho safrinha, por causa da intensa restrição hídrica após a fase de florescimento. As maiores produtividades foram obtidas para os plantios realizados no início do mês de fevereiro. As cultivares AG7088 PRO, AS1596 PRO e DKB310 PRO apresentaram maior estabilidade e potencial produtivo. A severidade da ferrugempolissora foi maior nos plantios realizados no início de fevereiro, e reduziu com o atraso na semeadura. As cultivares mais suscetíveis foram 30F53 YF e CD355.
\end{abstract}

Palavras-chave: milho safrinha, ferrugem-polissora, estresse hídrico.

\section{CORN CULTIVARS AFFECTED BY SOWING TIME AT OFF-SEASON IN TOCANTINS, BRAZIL}

\begin{abstract}
Water stress and occurrence of foliar diseases are the main challenges for the cultivation of off-season corn in Tocantins, which is carried out at the end of the rainy season. The objective of this work was to evaluate the effect of sowing season and foliar diseases on the performance of corn cultivars in the State of Tocantins, Brazil, at off-season. Eleven cultivars were evaluated in the 2014 and 2015 off-season. Sowing was performed on 02/03/2014, $02 / 25 / 2014,02 / 12 / 2015$ and $03 / 12 / 2015$. Randomized block experimental design was used in factorial arrangement $11 x 2$ (cultivars x sowing times). Differences were observed for the cultivar and sowing times for all variables studied. The delay in the sowing season drastically reduced the off-season corn yield, due to the intense water restriction after the flowering phase. Highest yields were obtained for the planting carried out at the beginning of February. The cultivars AG7088 PRO, AS1596 PRO and DKB310 PRO presented greater stability and yield potential. Southern rust severity was higher in the planting carried out in early February, and reduced with the sowing delay. The most susceptible cultivars were 30F53 YF and CD355.
\end{abstract}

Keywords: off-season corn, southern rust, water stress. 
A área de milho safrinha no Tocantins aumentou significativamente nos últimos anos. De 2013 para 2015, o aumento foi de 276\%, passando de 40,9 para 154 mil hectares (CONAB, 2016). No entanto, estes valores ainda são pequenos se considerado o grande potencial que o estado apresenta para a produção de milho safrinha. Nas safras 2014/2015 e 2015/2016, a relação entre as áreas de soja que foram cultivadas com milho safrinha no estado foi de, aproximadamente, 18 e 11\%, respectivamente. Estes números demonstram a existência de um grande espaço para o crescimento do milho safrinha, principalmente se comparado a outros estados, como Mato Grosso do Sul, Mato Grosso e Goiás, nos quais a relação de área de soja cultivada com milho safrinha foi de, aproximadamente, 68,41 e 38\%, respectivamente, no mesmo período (CONAB, 2016).

Uma das particularidades do cultivo de milho safrinha no Tocantins é a existência de um curto período de tempo entre a colheita da soja e o plantio do milho, porque o final das chuvas ocorre no mês de abril (Borghi et al., 2014), quando as lavouras se encontram em fase de florescimento ou enchimento de grãos. A viabilidade do cultivo do milho safrinha no Estado do Tocantins se deve ao uso de cultivares de soja de ciclo precoce (90 a 100 dias) e ao sistema de plantio direto (Borghi et al., 2014). Cultivares precoces permitem a colheita da soja mais cedo, e, com o sistema de plantio direto, a semeadura do milho pode ser realizada imediatamente após a colheita da soja, sem a necessidade das operações de preparo do solo, que demandariam um maior tempo entre a colheita e o plantio do milho safrinha. Com esta antecipação, é possível alocar as fases mais críticas do ciclo de desenvolvimento do milho durante as últimas chuvas que ocorrem nos meses de março e abril, que são fundamentais para a obtenção de maiores produtividades.
Dois dos principais fatores de sucesso do milho safrinha são a época de semeadura e a escolha correta dos híbridos a serem utilizados em cada local. As semeaduras realizadas no final de janeiro até meados de fevereiro apresentam maior potencial produtivo, pois as fases de florescimento e enchimento dos grãos ocorrem em abril, mês que, historicamente, se registra o final do período de excedente hídrico. Semeaduras mais tardias, no final de fevereiro e início de março, representam maiores riscos de frustração de safra, pois as fases críticas de florescimento e enchimento de grãos ocorrerão em situação de deficiência hídrica. Como a maioria dos solos apresenta baixa capacidade de retenção de água, a definição da época de semeadura torna-se ainda mais importante.

A escolha dos melhores híbridos para uma determinada região deve ser baseada nas variações climáticas que ocorrem em cada localidade e nas épocas de semeadura, já que, em cultivos extemporâneos, as cultivares mais bem adaptadas não são, necessariamente, aquelas mesmas dos plantios de verão (Duarte \& Paterniani, 1999). Características dos híbridos, como o ciclo, o potencial e a estabilidade produtiva e a reação das pragas e doenças, devem ser consideradas em cada localidade. Além disso, por causa da grande quantidade de híbridos disponíveis, da rápida substituição no mercado e da grande variabilidade de suas características agronômicas, torna-se necessário um contínuo trabalho de avaliação para identificar as cultivares mais bem adaptadas a cada condição de plantio. São escassas as informações científicas sobre o impacto das épocas de semeadura sobre o desenvolvimento e a produtividade do milho safrinha em Tocantins.

Chagas et al. (2015) relatam a importância do conhecimento das principais doenças do milho safrinha no estado, bem como o seu potencial de perdas. 
Segundo os autores, as principais doenças foliares do milho safrinha em Tocantins são a ferrugem-polissora, a mancha-de-bipolaris, a mancha-foliar-de-diplodia, a antracnose-foliar e os enfezamentos. Segundo Vaz-de-Melo et al. (2010), a mancha-de-curvularia tem ocorrido de forma frequente na região sul do Tocantins. No entanto, a ocorrência destas doenças é variável nos diferentes locais e anos, dependendo das condições de clima predominantes.

O presente trabalho teve como objetivo avaliar o desempenho de cultivares de milho em diferentes épocas de semeadura na safrinha, em Tocantins.

\section{Material e Métodos}

Foram conduzidos dois experimentos na área da Unidade de Aprendizado Tecnológico (UAT) da Embrapa, localizada na área da Agrotins (-10.400675 S, -48.362223 W), no município de Palmas-TO. O clima da região é caracterizado por verão chuvoso e inverso seco. O solo é classificado como Latossolo
Vermelho Distrófico Típico (Santos et al., 2013). Foram avaliados onze híbridos de milho (Tabela 1) em duas épocas de semeadura, no período da safrinha, nos anos de 2014 e 2015. Utilizou-se o delineamento experimental de blocos ao acaso, com os tratamentos dispostos em arranjo fatorial $11 \times 2$ (cultivares $\mathrm{x}$ época de semeadura), com 22 tratamentos e quatro repetições.

As semeaduras da primeira e segunda épocas foram realizadas nos dias 03/02/2014 e 25/02/2014, na safrinha de 2014, e nos dias 12/02/2015 e $12 / 03 / 2015$, na safrinha de 2015. Foram utilizados os híbridos simples 2B587 PW, 30F53 YH, AG7088 PRO, AS1596 PRO, BRS1060, CD355, DKB310 PRO, DKB390 PRO e RB9308 YG, e os híbridos duplos BALU761 e BRS2020.

A semeadura foi realizada no sistema de plantio direto, com 22,5 $\mathrm{kg} \mathrm{ha}^{-1}$ de $\mathrm{N}, 112,5 \mathrm{~kg} \mathrm{ha}^{-1}$ de $\mathrm{P}_{2} \mathrm{O}_{5}$, e 67,5 kg ha-1 de $\mathrm{K}_{2} \mathrm{O}$ mais $30 \mathrm{~kg}$. ha- ${ }^{-1}$ de nitrogênio na forma de ureia, na fase V4 (quatro folhas completamente expandidas), em sulco entre as linhas

Tabela 1. Descrição das cultivares de milho utilizadas nos experimentos em 2014 e 2015.

\begin{tabular}{lccc}
\hline \multicolumn{1}{c}{ Cultivares } & Tipo & Ciclo & Evento \\
\hline AG7088 PRO & Híbrido simples & Precoce & MON 89034 \\
AS1596 PRO & Híbrido simples & Precoce & MON 89034 \\
BALU761 & Híbrido duplo & Precoce & - \\
BRS1060 & Híbridos simples & Semiprecoce & - \\
BRS2020 & Híbrido duplo & Precoce & - \\
CD355 & Híbridos simples & Precoce & - \\
DKB310 PRO & Híbridos simples & Semiprecoce & MON 89034 \\
DKB390 PRO & Híbridos simples & Precoce & MON 89034 \\
2B587 PW & Híbridos simples & Precoce & MON 89034, TC1507 e NK603 \\
30F53 YH & Híbridos simples & Precoce & TC1507 \\
RB9308 YG & Híbridos simples & Precoce & MON 810 \\
\hline
\end{tabular}


de plantio. As parcelas foram constituídas por quatro linhas de cinco metros, com espaçamento de $0,5 \mathrm{~m}$ entre linhas. Para as avaliações e colheita foram utilizadas, como área útil, as duas linhas centrais de cada parcela. Após a emergência das plantas, foi realizado o desbaste para o ajuste da população final de 55.000 plantas.ha-1 ${ }^{-1}$ Foi realizada uma aplicação de fungicida (Epoxiconazole + Piraclostrobina, 0,75 L.ha ${ }^{-1}$ ) na fase V8 (oito folhas completamente expandidas). As aplicações de fungicida foram realizadas utilizando-se um pulverizador manual pressurizado a $\mathrm{CO} 2$, com vazão constante de 250 L ha-1 e adição de óleo mineral na dose de $0,5 \%$ do volume de calda.

Ao longo do ciclo da cultura foram realizadas duas avaliações da severidade de doenças foliares, aos 80 e 95 DAE (dias após a emergência). Para tal, utilizou-se uma escala de notas variando de $1(0 \%$ de severidade) a 5 (100\% das folhas com lesões, acima de 75\% de severidade) (Agroceres, 1996). Foi atribuída uma nota média de severidade para cada doença em cada parcela. Além das avaliações de doenças, foram determinadas a altura média de plantas e a altura média de espigas em cada parcela. Para tal, foram medidas seis plantas aleatórias de cada cultivar.

Ao final do ciclo, foram colhidas e contadas todas as espigas das duas linhas centrais de cada parcela, as quais foram identificadas e pesadas (espigas e grãos) separadamente. Foi determinado o número de fileiras por espiga, número de grãos por espiga, peso de 1.000 grãos, umidade dos grãos e peso total de grãos (PTG). Para a determinação da produtividade, os dados de PTG foram corrigidos para 13\% de umidade e a produtividade foi expressa em kg.ha-1 ${ }^{-1}$ No momento da colheita, foi medida a altura de plantas e espigas em cinco plantas, aleatoriamente, em cada parcela.

Os dados de precipitação, temperatura, umidade do ar, radiação solar global e velocidade do ven- to foram obtidos através da estação meteorológica localizada na área experimental. Estes dados foram utilizados para o cálculo da Evapotranspiração Potencial (ET0), pelo método de Penman-Monteith. Com os dados de temperatura, precipitação e ET0, foram elaborados os balanços hídricos de 2014 e 2015, seguindo o roteiro proposto por Thornthwaite \& Matter (1955) e Camargo (1962).

Os dados de médias de cada variável foram submetidos à análise de variância conjunta (anos) e as médias, quando necessário, foram comparadas ao nível de 5\% de probabilidade pelo teste Scott-Knott, com o uso do programa estatístico Sisvar, versão 5.6.

\section{Resultados e Discussão}

De acordo com a análise de variância houve diferenças significativas $(P \leq 0,05)$ para os fatores cultivar e épocas de semeadura para todas as variáveis analisadas, nos dois anos. A interação Cultivar x Épocas de semeadura foi significativa apenas para a variável peso de 1.000 grãos e severidade da ferrugem-polissora no ano de 2014 e para peso de 1.000 grãos, produtividade e severidade da ferrugem-polissora no ano de 2015.

A aplicação de fungicida no experimento foi realizada com o objetivo de permitir a expressão do máximo potencial produtivo das cultivares em função das épocas de semeadura. No entanto, apesar dessa aplicação, foi observada elevada severidade da ferrugem-polissora na área experimental. Outras doenças, como a mancha-de-bipolaris (Bipolaris maydis (Nisikado) Shoemaker) e a antracnose-foliar (Colletotrichum graminicola (Ces.) G.W. Wils.) também ocorreram, porém, em severidade muito baixa, não permitindo uma discriminação entre os híbridos e épocas de semeadura. A elevada severidade da fer- 
rugem-polissora, apesar da aplicação do fungicida, pode ser explicada por dois fatores principais: época de aplicação e período residual dos fungicidas. Segundo Costa \& Cota (2009), as doenças na cultura do milho ocorrem de forma mais severa a partir da fase reprodutiva das plantas. Portanto, como a aplicação foi realizada na fase de oito folhas, no momento do florescimento praticamente não havia efeito residual ou protetivo dos ingredientes ativos para o controle da doença, a qual se desenvolveu rapidamente nos cultivares mais suscetíveis, o que pode ser verificado pelas notas de severidade.

$\mathrm{Na}$ primeira época de semeadura de 2014, as menores notas de severidade da ferrugem-polissora foram observadas para os híbridos AS1596 PRO, 2B587 PW, AG7088 PRO, DKB310 PRO e BRS1060 (Tabela 2). Os híbridos CD355 e 30F53YH apresentaram as maiores notas de severidade, 4,13 e 5,0, respectivamente. Na segunda época de semeadura deste ano, apenas as cultivares CD355, com nota de 2,62, e 30F53YH, nota 4,0, diferiram das demais cultivares. No ano de 2015, foi verificada diferença entre as cultivares apenas na primeira época de semeadura. Novamente, as cultivares CD355 e 30F53YH diferiram das demais pela suscetibilidade à ferrugem-polissora, cujas notas foram 2,62 e 5,0, respectivamente (Tabela 3). Costa et al. (2016), em ensaios de avaliação de cultivares de milho, obtiveram resultados semelhantes quanto a suscetibilidade das cultivares CD355 e 30F53 YH. Esses resultados evidenciam a necessidade de cuidado com a ocorrência da ferrugem-polissora nas condições de plantio do Cerrado, em baixas altitudes, como as do Estado do Tocantins. Segundo Costa et al. (2015), epidemias severas da ferrugem-polissora ocorrem em condições de baixas altitudes $(>700 \mathrm{~m})$ e temperatura elevadas. Em cultivares suscetíveis, como CD355 e 30F53 YH, uma aplicação de fungicida nas fases iniciais do ciclo do milho não é suficiente para o controle da doença e prevenção das perdas por elas causadas, de acordo com os dados do presente trabalho.

Segundo Magalhães \& Durães (2006), os componentes da produtividade número de fileiras por espigas, tamanho das espigas e número de grãos por fileira são definidos durante o período vegetativo, nos estágios V8, V12, V17, respectivamente, e o componente peso de 1.000 grãos é definido durante os estágios reprodutivos do milho. No ano de 2014, o período vegetativo do milho, em ambas as épocas de semeadura, ocorreu em situação de excedente hídrico (Figura 1A), e, por isso, não houve diferença de NFE e NGE entre as épocas de semeadura (Tabela 2). As cultivares BRS 2020 e BALU 761 obtiveram os menores números destas variáveis por serem híbridos duplos, e terem menor potencial produtivo em relação aos demais híbridos simples. O comportamento, quanto ao potencial produtivo, de híbridos simples, duplos e triplos é conhecido há bastante tempo. Stringfield (1950) verificou uma redução de 3,5\% no rendimento médio de grãos dos híbridos duplos em relação aos híbridos simples. Eberhart e Russel (1969) verificaram uma superioridade média de 2,9\% dos híbridos simples sobre os híbridos duplos quanto a estabilidade e potencial produtivo, e Wheatherspoon (1970), ao comparar o potencial produtivo de 36 híbridos simples, 36 híbridos triplos e 36 híbridos duplos de milho, verificou a superioridade média dos híbridos simples sobre os triplos e desses sobre os duplos.

O peso de 1.000 grãos em 2014 foi diferente entre as épocas de semeadura (Tabela 2), uma vez, que na época 2, a maior parte do período reprodutivo ocorreu em condição de deficiência hídrica (Figura 1A), fator que reduziu o $\mathrm{P} 1000 \mathrm{~g}$ para todos os 
Tabela 2. Notas de severidade da ferrugem-polissora, número de fileiras por espiga (NFE), número de grãos por espiga (NGE), altura de plantas (AP), altura de espigas (AE), peso de mil grãos (P1000g) e produtividade (PROD) de cultivares de milho, semeadas em duas épocas, na safrinha de 2014, em Tocantins.

\begin{tabular}{|c|c|c|c|c|c|c|c|c|c|}
\hline \multirow{2}{*}{ CULTIVARES } & \multicolumn{2}{|c|}{ Ferrugem polissora } & \multirow{2}{*}{ NFE } & \multirow{2}{*}{ NGE } & \multirow{2}{*}{$\mathrm{AP}$} & \multirow{2}{*}{$\mathrm{AE}$} & \multicolumn{2}{|c|}{ P1000g } & \multirow{2}{*}{ PROD } \\
\hline & $1^{\mathrm{a}}$ Época & $2^{\mathrm{a}}$ Época & & & & & $1^{\mathrm{a}}$ Época & $2^{a}$ Época & \\
\hline DKB310 PRO & $1,75 \mathrm{a}^{1}$ & $1,75 \mathrm{a}$ & $16,8 \mathrm{~d}$ & $483 \mathrm{~d}$ & $200 \mathrm{c}$ & $111,5 \mathrm{~d}$ & 327,4 Ad & $293,5 \mathrm{Bd}$ & $7.982 \mathrm{c}$ \\
\hline BRS 1060 & $1,87 \mathrm{a}$ & $1,50 \mathrm{a}$ & $14,5 \mathrm{~b}$ & $463 \mathrm{c}$ & $166 \mathrm{a}$ & $78,2 \mathrm{a}$ & $309,6 \mathrm{Ac}$ & $256,9 \mathrm{Bc}$ & $6.708 \mathrm{~b}$ \\
\hline BALU761 & $2,87 \mathrm{~b}$ & $1,87 \mathrm{a}$ & $13,7 \mathrm{a}$ & $429 \mathrm{~b}$ & $187 \mathrm{~b}$ & $99,1 \mathrm{c}$ & $306,1 \mathrm{Ac}$ & $297,3 \mathrm{Ad}$ & $7.041 \mathrm{~b}$ \\
\hline AS1596 PRO & $1,37 \mathrm{a}$ & $1,50 \mathrm{a}$ & $17,6 \mathrm{e}$ & $533 \mathrm{~d}$ & $203 \mathrm{c}$ & $111,2 \mathrm{~d}$ & $298,2 \mathrm{Ab}$ & $261,4 \mathrm{Bc}$ & $8.112 \mathrm{c}$ \\
\hline BRS2020 & $2,75 \mathrm{~b}$ & $1,75 \mathrm{a}$ & $13,1 \mathrm{a}$ & $383 \mathrm{a}$ & $185 \mathrm{~b}$ & $92,7 \mathrm{~b}$ & $298,0 \mathrm{Ab}$ & $288,0 \mathrm{Ad}$ & $5.425 \mathrm{a}$ \\
\hline 2B587 PW & $1,50 \mathrm{a}$ & $1,62 \mathrm{a}$ & $15,7 \mathrm{c}$ & $505 \mathrm{~d}$ & $177 \mathrm{~b}$ & $84,5 \mathrm{a}$ & $291,9 \mathrm{Ab}$ & $260,2 \mathrm{Bc}$ & $7.172 \mathrm{~b}$ \\
\hline DKB390 PRO & $2,62 \mathrm{~b}$ & $2,00 \mathrm{a}$ & $16,7 \mathrm{~d}$ & $493 \mathrm{~d}$ & $182 \mathrm{~b}$ & $103,7 \mathrm{c}$ & $286,9 \mathrm{Ab}$ & $265,5 \mathrm{Bc}$ & $7.395 \mathrm{~b}$ \\
\hline CD355 & $4,13 \mathrm{c}$ & $2,62 \mathrm{~b}$ & $15,0 \mathrm{~b}$ & $510 \mathrm{~d}$ & $194 \mathrm{c}$ & $114,9 \mathrm{~d}$ & $277,1 \mathrm{Aa}$ & $247,9 \mathrm{Bb}$ & $7.449 \mathrm{~b}$ \\
\hline RB9308 YG & $2,62 \mathrm{~b}$ & $1,87 \mathrm{a}$ & $16,4 \mathrm{~d}$ & $514 \mathrm{~d}$ & $224 d$ & $122,4 \mathrm{e}$ & $263,6 \mathrm{Aa}$ & $243,4 \mathrm{Bb}$ & $6.677 \mathrm{~b}$ \\
\hline AG7088 PRO & $1,50 \mathrm{a}$ & $1,37 \mathrm{a}$ & $18,5 \mathrm{e}$ & $615 \mathrm{e}$ & $205 \mathrm{c}$ & $111,3 \mathrm{~d}$ & $262,6 \mathrm{Aa}$ & $243,2 \mathrm{Bb}$ & $8.061 \mathrm{c}$ \\
\hline $30 \mathrm{~F} 53 \mathrm{YH}$ & $5,00 \mathrm{~d}$ & $4,00 \mathrm{c}$ & $15,8 \mathrm{c}$ & $500 \mathrm{~d}$ & $194 \mathrm{c}$ & $104,8 \mathrm{c}$ & $248,9 \mathrm{Aa}$ & $171,7 \mathrm{Ba}$ & $5.521 \mathrm{a}$ \\
\hline Épcoa 1 & - & - & $15,8 \mathrm{a}$ & $499 \mathrm{a}$ & $202 \mathrm{~b}$ & $102,2 \mathrm{a}$ & -- & -- & $7.530 \mathrm{~b}$ \\
\hline Época 2 & - & - & $15,7 \mathrm{a}$ & $488 \mathrm{a}$ & $183 \mathrm{a}$ & $104,0 \mathrm{a}$ & -- & -- & $6.568 \mathrm{a}$ \\
\hline CV $(\%)$ & \multicolumn{2}{|c|}{19,1} & 4,98 & 6,56 & 4,85 & 7,65 & \multicolumn{2}{|c|}{4,78} & 12,8 \\
\hline
\end{tabular}

${ }^{1}$ Médias seguidas pela mesma letra minúscula na coluna e maiúscula na linha não diferem entre si ao nível de $5 \%$ de probabilidade pelo teste Scott-Knott.

híbridos, com exceção de BRS 2020 e BALU 761, que, por serem híbridos duplos, são mais resistentes aos estresses ambientais. Resultados semelhantes foram obtidos por Machado et al. (2008) e Costa et al. (2010). Segundo os autores, pela análise da contribuição de cada tipo de híbrido para a interação genótipo $\mathrm{x}$ ambiente, os híbridos duplos apresentaram maior estabilidade produtiva do que os híbridos triplos e simples em diferentes ambientes.

A produtividade de milho em 2014 foi maior na época 1, por causa da redução do P1000 grãos da época 2 (Tabela 2). Os híbridos BRS 2020 e 30F53 YH foram os menos produtivos em razão dos me- nores valores dos componentes de produtividade no caso do primeiro, e da maior severidade da ferrugem-polissora no caso do segundo. Os híbridos mais produtivos foram o DKB310 PRO, AS1596 PRO e AG 7088 PRO, por serem híbridos simples, com os melhores índices dos componentes de produtividade, associado à menor ocorrência da ferrugem-polissora.

Na safrinha de 2015, a ocorrência de chuvas foi mais restrita e a diferença de data entre as épocas de semeadura foi maior. No caso da primeira época, a semeadura e o florescimento ocorreram em período de excedente hídrico, com fases de deficiência hídrica durante o desenvolvimento vegetativo e reprodutivo 
Tabela 3. Notas de severidade da ferrugem-polissora, número de fileiras por espiga (NFE), número de grãos por espiga (NGE), altura de plantas (AP), altura de espigas (AE), peso de 1.000 grãos (P1000g) e produtividade (PROD) de cultivares de milho, semeadas em duas épocas, na safrinha de 2015, em Tocantins.

\begin{tabular}{|c|c|c|c|c|c|c|c|c|c|c|}
\hline \multirow{2}{*}{ Cultivares } & \multicolumn{2}{|c|}{ Ferrugem Polissora } & \multirow{2}{*}{ NFE } & \multirow{2}{*}{ NGE } & \multirow{2}{*}{$\mathrm{AP}$} & \multirow{2}{*}{$\mathrm{AE}$} & \multicolumn{2}{|c|}{ P1000g } & \multicolumn{2}{|c|}{ PROD } \\
\hline & $1^{\text {a }}$ Época & $2^{\text {a }}$ Época & & & & & $1^{\mathrm{a}}$ Época & $2^{\mathrm{a}}$ Época & $1^{\text {a }}$ Época & $2^{\mathrm{a}}$ Época \\
\hline DKB310 PRO & $1,37 \mathrm{a}^{1}$ & $1,50 \mathrm{a}$ & $15,5 \mathrm{c}$ & $387,8 \mathrm{~b}$ & $154 \mathrm{a}$ & $69 a$ & $312,2 \mathrm{Ab}$ & $164,7 \mathrm{Bb}$ & $7.389 \mathrm{Ac}$ & $5.460 \mathrm{Bb}$ \\
\hline AG7088 PRO & $1,50 \mathrm{a}$ & $1,37 \mathrm{a}$ & $17,3 \mathrm{~d}$ & $500,6 \mathrm{~d}$ & $172 b$ & $83 \mathrm{~b}$ & $246,3 \mathrm{Ab}$ & $158,9 \mathrm{Bb}$ & $7.387 \mathrm{Ac}$ & $4.980 \mathrm{Bb}$ \\
\hline 2B587 PW & $1,50 \mathrm{a}$ & $1,75 \mathrm{a}$ & $15,2 \mathrm{c}$ & $416,9 \mathrm{c}$ & $178 \mathrm{c}$ & $91 \mathrm{~b}$ & $267,6 \mathrm{Ab}$ & $150,7 \mathrm{Bb}$ & $7.292 \mathrm{Ac}$ & $3.600 \mathrm{Ba}$ \\
\hline BRS1060 & $1,25 \mathrm{a}$ & $1,50 \mathrm{a}$ & $12,7 \mathrm{a}$ & $302,5 \mathrm{a}$ & $178 \mathrm{c}$ & $91 \mathrm{~b}$ & $265,8 \mathrm{Ab}$ & $212,4 \mathrm{Bc}$ & $7.147 \mathrm{Ac}$ & $3.540 \mathrm{Ba}$ \\
\hline BALU761 & $1,75 \mathrm{a}$ & $1,75 \mathrm{a}$ & $14,1 \mathrm{~b}$ & $370,4 \mathrm{~b}$ & $170 \mathrm{~b}$ & $85 \mathrm{~b}$ & $291,0 \mathrm{Ab}$ & $156,6 \mathrm{Bb}$ & $6.875 \mathrm{Ac}$ & $3.480 \mathrm{Ba}$ \\
\hline AS1596 PRO & $1,50 \mathrm{a}$ & $1,50 \mathrm{a}$ & $16,5 \mathrm{~d}$ & $442,0 \mathrm{c}$ & $158 \mathrm{a}$ & $69 \mathrm{a}$ & $275,5 \mathrm{Ab}$ & $145,5 \mathrm{Bb}$ & $6.758 \mathrm{Ac}$ & $4.560 \mathrm{Bb}$ \\
\hline DKB390 PRO & $1,50 \mathrm{a}$ & $1,62 \mathrm{a}$ & $15,3 \mathrm{c}$ & $372,5 \mathrm{~b}$ & $168 \mathrm{~b}$ & $84 \mathrm{~b}$ & $273,8 \mathrm{Ab}$ & $141,0 \mathrm{Bb}$ & $6.579 \mathrm{Ac}$ & $4.620 \mathrm{Bb}$ \\
\hline CD355 & $2,62 \mathrm{~b}$ & $1,62 \mathrm{a}$ & $14,7 \mathrm{c}$ & $395,2 \mathrm{~b}$ & $169 \mathrm{~b}$ & $86 \mathrm{~b}$ & $257,1 \mathrm{Ab}$ & $142,1 \mathrm{Bb}$ & $5.770 \mathrm{Ab}$ & $3.480 \mathrm{Ba}$ \\
\hline RB9308 YG & $1,50 \mathrm{a}$ & $1,87 \mathrm{a}$ & $14,9 \mathrm{c}$ & $391,9 \mathrm{~b}$ & $176 \mathrm{c}$ & $95 \mathrm{~b}$ & $203,0 \mathrm{Aa}$ & $127,5 \mathrm{Ba}$ & $5.336 \mathrm{Ab}$ & $3.360 \mathrm{Ba}$ \\
\hline BRS2020 & $1,50 \mathrm{a}$ & $1,50 \mathrm{a}$ & $12,3 \mathrm{a}$ & $320,0 \mathrm{a}$ & $165 \mathrm{~b}$ & $88 \mathrm{~b}$ & $259,4 \mathrm{Ab}$ & $148,3 \mathrm{Bb}$ & $4.885 \mathrm{Aa}$ & $3.060 \mathrm{Ba}$ \\
\hline 30F53 YH & $5,00 \mathrm{c}$ & $2,00 \mathrm{a}$ & $14,3 \mathrm{~b}$ & $400,1 \mathrm{~b}$ & $181 \mathrm{c}$ & $86 \mathrm{~b}$ & $214,7 \mathrm{Aa}$ & $98,8 \mathrm{Ba}$ & $4.351 \mathrm{Aa}$ & $2.640 \mathrm{Ba}$ \\
\hline Épcoa 1 & - & - & $15,4 \mathrm{~b}$ & $481,0 \mathrm{~b}$ & $174 \mathrm{~b}$ & $86 \mathrm{a}$ & & & & \\
\hline Época 2 & - & - & $14,2 \mathrm{a}$ & $300,8 \mathrm{a}$ & $165 \mathrm{a}$ & $83 \mathrm{a}$ & & & & \\
\hline$\overline{C V}(\%)$ & 15 & & 7,86 & 14,29 & 6,36 & 11,15 & & & & \\
\hline
\end{tabular}

${ }^{1}$ Médias seguidas pela mesma letra minúscula na coluna e maiúscula na linha não diferem entre si ao nível de 5\% de probabilidade pelo teste Scott-Knott.

(Figura 1B). Na segunda época, a semeadura e o florescimento ocorreram em momentos de deficiência hídrica, e o milho teve menor quantidade de chuvas durante o ciclo quando comparada à primeira época. Por este motivo, todos os híbridos apresentaram maior NFE, NGE, AP e P1000g e, por consequência, maior produtividade, quando semeados na primeira época (Tabela 3). Na primeira época em 2015, os híbridos menos produtivos foram 30F53 YH e BRS 2020, em razão da maior severidade da ferrugem-polissora, no caso do primeiro, e do menor desempenho de NFE e NGE em relação aos demais, causado pelo período de deficiência hídrica durante o período vegetativo, no caso do híbrido BRS 2020.
Ainda na safrinha de 2015, na semeadura mais tardia, com intensa ocorrência de deficiência hídrica durante o ciclo da cultura, os híbridos mais produtivos foram DKB 310 PRO, AG 7088 PRO, DKB 390 PRO e AS 1596 PRO, os quais apresentaram os menores índices de severidade da ferrugem-polissora, e os maiores de NFE, NGE e P1000g.

Segundo Gontijo Neto et al. (2013), em ensaios de avaliação de cultivares de milho em Rio Verde-GO, as cultivares AG7088 PRO, AS1596 PRO, DKB390 PRO e 2B587 PW foram as mais produtivas, com médias entre 8.083 e $9.304 \mathrm{Kg} \mathrm{ha}^{-1}$. No presente trabalho, as cultivares AG7088 PRO, AS1596 PRO, DKB390 PRO também se destacaram como as 

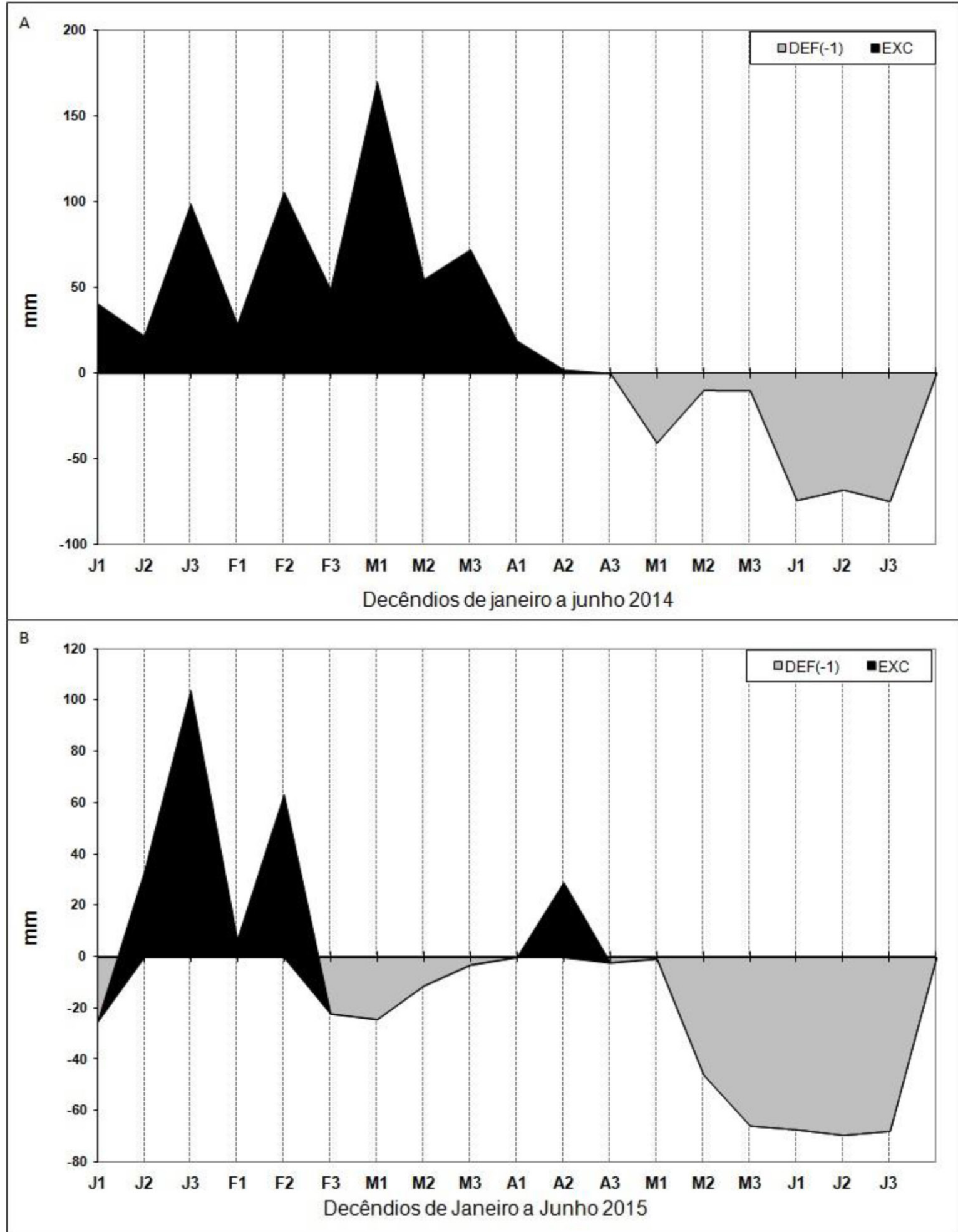

Figura 1. Balanço hídrico da área experimental em Palmas-TO de janeiro a junho dos anos de 2014 (A) e 2015 (B). Legenda: Deficiência hídrica - DEF(-1); Excedente hídrico - EXC. 
mais produtivas nos dois anos de estudo. Em ensaio de avaliação de cultivares conduzido em Montividiu-GO, a cultivar DKB390 se destacou entre as mais produtivas, enquanto a cultivar AG7088 apresentou produtividade relativamente baixa quando comparada às demais cultivares (Silva et al., 2014). Essas diferenças observadas na literatura evidenciam a importância da avaliação local, visando a seleção dos materiais mais adaptados a uma região.

Uma das particularidades do cultivo de milho safrinha no Estado do Tocantins é o curto período de tempo entre a colheita da soja e o plantio do milho, por causa da concentração do volume de chuvas em alguns meses do ano (Borghi et al., 2014). O atraso da semeadura na safrinha do Tocantins reduz a quantidade de chuvas disponível durante o ciclo da cultura, o que resulta em decréscimo do potencial produtivo. Em 2014, a média de produtividade foi 12,7\% menor na segunda época de semeadura em relação à primeira, cujos valores foram de $7.530 \mathrm{Kg} \mathrm{ha}^{-1}$ na primeira época e $6.568 \mathrm{Kg} \mathrm{ha}^{-1}$ na segunda (Tabela 2). Em 2015, o atraso entre as épocas foi maior e a safrinha menos chuvosa (Figura 1B) e, por isso, a redução da produtividade foi mais acentuada. Na média das cultivares, o milho produziu 38,6\% menos na época $2 \mathrm{em}$ relação à época 1 (Tabela 3 ).

O período de enchimento dos grãos do milho safrinha em Tocantins ocorre justamente durante o encerramento da estação chuvosa. Desta forma, quanto mais cedo for realizada a semeadura do milho safrinha, mais tempo a fase reprodutiva estará no período de excedente hídrico e, assim, maior o potencial de enchimento e peso de grãos. Neste trabalho, a época 2 apresentou grãos 10,7\% mais leves em 2014 e 42,5\% em 2015 em relação à época 1, na média das cultivares. A maior redução em P1000g em 2015 em relação a 2014 ocorreu em razão de: (i) a diferença entre o plantio das épocas 1 e 2, que foi de 22 dias em 2014 e de 28 dias em 2015; (ii) a semeadura de 2015 mais tardia, com a última época 2 no mês de março, e o florescimento em abril; e (iii) a safrinha de 2014 foi mais chuvosa, em cerca de $500 \mathrm{~mm}$, do que a de 2015 (Figura 1A e B).

As fases mais críticas das plantas de milho como relação à exigência hídrica se concentram na emergência, no florescimento e no enchimento dos grãos (Silva et al., 2010). Segundo os mesmos autores, períodos de deficiência hídrica de uma semana por ocasião do pendoamento podem reduzir a produção em até $50 \%$, ao passo que, sob as mesmas condições, a deficiência hídrica após o início da formação de grãos pode acarretar perdas entre 25 e $37 \%$. De acordo com Aldrich et al. (1982), dois dias de estresse hídrico no florescimento diminui o rendimento em mais de $20 \%$ e, de quatro a oito dias, em mais de $50 \%$. O maior consumo de água na cultura do milho ocorre entre as fases do florescimento e grãos leitosos, 5,0 a $7,5 \mathrm{~mm} /$ dia (Shioga \& Gerage, 2010). Por causa dos baixos índices de chuva no período e da baixa capacidade de retenção de água da maioria dos solos do Estado do Tocantins, o sucesso do milho safrinha depende, principalmente, da época de semeadura.

Os resultados obtidos no presente trabalho demonstram que a produtividade média das cultivares está intimamente relacionada ao volume e à distribuição das chuvas durante o seu período de cultivo. Esta relação pode ser melhor visualizada na Figura 2. No ano de 2014, as cultivares semeadas em 03/02/2014 floresceram no final do mês de março, período com excedente hídrico que durou até final de abril, suficiente para o desenvolvimento e enchimento dos grãos, que garantiu produtividade média de $7.530 \mathrm{Kg}$ $\mathrm{ha}^{-1}$. Na semeadura realizada em 25/02/2014, o florescimento ocorreu na metade do mês de abril, também 


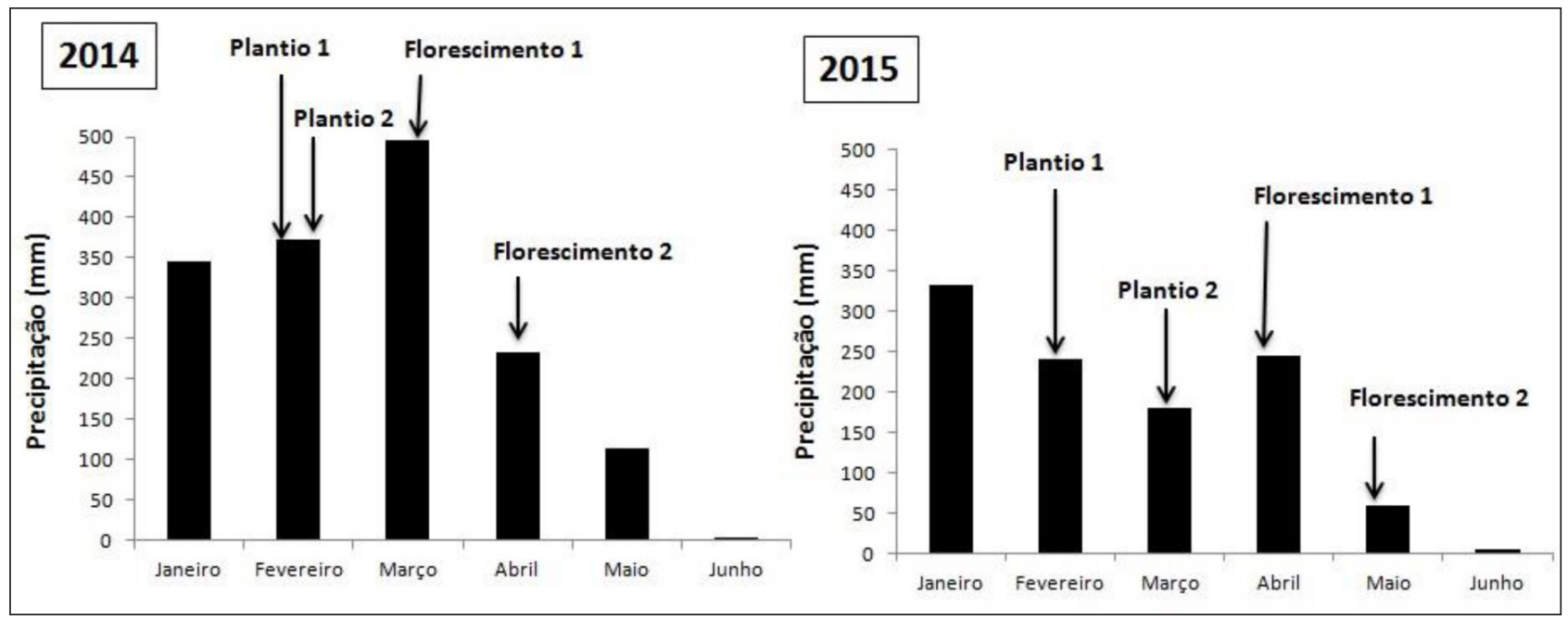

Figura 2. Produtividade média de cultivares de milho em função da época de semeadura e da disponibilidade de precipitação no período de cultivo do milho safrinha no Estado do Tocantins, nos anos de 2014 e 2015.

em situação de excedente hídrico, mas com menor disponibilidade de água para o enchimento dos grãos em relação à época 1 , mas ainda com produtividade de $6.568 \mathrm{Kg} \mathrm{ha}^{-1}$, que resultou em diferença de apenas $962 \mathrm{Kg} \mathrm{ha}^{-1}$ entre as épocas de 2014.

Em 2015, o volume de chuvas registrado na safrinha foi cerca de $500 \mathrm{~mm}$ a menos do que no ano anterior. $\mathrm{Na}$ primeira semeadura, realizada em 12/02/2015, o florescimento ocorreu no início do mês de abril, período de excedente hídrico, mas com maior intensidade de períodos de deficiência hídrica em relação à safra passada. E, por isso, a produtividade média foi de $6.343 \mathrm{Kg} \mathrm{ha}^{-1}$. Na semeadura de 12/03/2015, o florescimento ocorreu no início de maio, no final do período chuvoso, sob intensa deficiência hídrica, fato que limitou a produtividade média em $3.889 \mathrm{Kg} \mathrm{ha}^{-1}$. A diferença entre as épocas de plantio neste ano foi de 2.454 $\mathrm{Kg} \mathrm{ha}^{-1}$.

Os resultados obtidos no presente trabalho demonstram o elevado risco da ocorrência de deficiência hídrica durante as fases de florescimento e enchimen- to de grãos do milho safrinha no Estado do Tocantins. Portanto, para a obtenção de maiores níveis de produtividade, o milho safrinha deve ser cultivado o mais cedo possível, evitando-se plantios a partir do final de fevereiro. Além disso, cuidados são necessários para o manejo da ferrugem-polissora, principalmente nas cultivares mais suscetíveis.

\section{Conclusões}

O atraso na época de semeadura reduziu a produtividade da cultura do milho safrinha no Estado do Tocantins. As maiores produtividades foram obtidas para os plantios realizados no início do mês de fevereiro.

As cultivares AG7088 PRO, AS1596 PRO e DKB310 PRO apresentaram maior estabilidade e potencial produtivo entre as cultivares avaliadas.

A ferrugem-polissora ocorreu em elevada severidade, principalmente nos plantios realizados no início do mês de fevereiro. Os cultivares mais suscetíveis à referida doença foram 30F53 YF e CD355. 


\section{Agradecimentos}

Os autores agradecem à Embrapa Milho e Sorgo e Embrapa Pesca e Aquicultura pelo suporte financeiro.

\section{Referências}

AGROCERES. Guia Agroceres de sanidade. São Paulo: Sementes Agroceres, 1996. $72 \mathrm{p}$.

ALDRICH, S. R.; SCOTT, W. O.; LENG, R. E. Modern corn production. 2. ed. Champaign: A \& L Publication, 1982. $371 \mathrm{p}$.

BORGHI, E.; BORTOLON, L.; AVANZI, J. C.; BORTOLON, E. S. O.; UMMUS, M. E.; GONTIJO NETO, M. M.; COSTA, R. V. Desafios das novas fronteiras agrícolas de produção de milho e sorgo no Brasil: desafios da região do MATOPIBA. In: KARAM, D.; MAGALHÃES, P. C. (Ed.). Eficiência nas cadeias produtivas e o abastecimento global. Sete Lagoas: Associação Brasileira de Milho e Sorgo, 2014. cap. 25, p. 263-278.

CAMARGO, A. P. Contribuição para a determinação da evapotranspiração potencial no Estado de São Paulo. Bragantia, Campinas, v. 21, p. 163-203, 1962.

DOI: $10.1590 / \mathrm{S} 0006-87051962000100012$.

CHAGAS, J. F. R.; SANTOS, G. R. dos; COSTA, R. V. da; COTA, L. V.; SILVA, D. D. da; SIMON, J.; MOURAO, D. de S. C. Principais doenças foliares da cultura do milho no Estado do Tocantins. Sete Lagoas: Embrapa Milho e Sorgo, 2015. 13 p. (Embrapa Milho e Sorgo. Circular Técnica, 213).

CONAB. Companhia Nacional de Abastecimento. Acompanhamento da safra brasileira: grãos: safra 2015/16: $7^{\circ}$ levantamento. Brasília, DF, 2016.

COSTA, E. F. N.; SOUZA, J. C. de; LIMA. J. L.; CARDOSO, G. A. Interação entre genótipos e ambientes em diferentes tipos de híbridos de milho. Pesquisa Agropecuária Brasileira, Brasília, DF, v. 45, n. 12, p. 1433-1440, dez. 2010.
COSTA, R. V. da; SILVA, D. D. da; COTA, L. V. Reação de cultivares de milho à ferrugem-polissora em casa de vegetação. Sete Lagoas: Embrapa Milho e Sorgo, 2015. 5 p. (Embrapa Milho e Sorgo. Circular Técnica, 214).

COSTA, R. V. da; COTA, L. V. Controle químico de doenças na cultura do milho: aspectos a serem considerados na tomada de decisão sobre aplicação. Sete Lagoas: Embrapa Milho e Sorgo, 2009. 11 p. (Embrapa Milho e Sorgo. Circular Técnica, 125).

COSTA, R. V. da; SIMON, J.; ALMEIDA, R. E. M. de; SILVA, D. D. da; COTA, L. V.; CAMPOS, L. J. M. Avaliação de cultivares de milho em diferentes épocas de plantio no Estado do Tocantins. Sete Lagoas: Embrapa Milho e Sorgo, 2016. 22 p. (Embrapa Milho e Sorgo. Boletim de Pesquisa e Desenvolvimento, 139).

DUARTE, A. P.; PATERNIANI, M. E. A. G. Z. (Coord.). Cultivares de milho no Estado de São Paulo: resultados das avaliações regionais IAC/CATI/EMPRESAS - 1997/98. Campinas: IAC, 1999. 97 p. (IAC. Documentos, 62).

EBERHART, S. A.; RUSSEL, W. A. yield and stability for a 10-line diallel of single-cross and double-cross maize hybrid. Crop Science, Madison, v. 9, p. 357-361, 1969. DOI: $10.2135 /$ cropsci1969.0011183X000900030034x.

GONTIJO NETO, M. M.; MAY, A.; CRUVINEL, W.; VANIN, A.; SILVA, A. F. da; SIMÃO, E. de P.; BARCELOS, V. G. Avaliação de cultivares de milho e épocas de semeadura na safrinha na região de Rio Verde-GO. In: WORKSHOP CTC AGRICULTURA, 12., 2013, Rio Verde. Resultados 2013. Rio Verde: Centro Tecnológico Comigo, 2013. p. 44-47.

MACHADO, J. C.; SOUZA, J. C. de; RAMALHO, M. A. P.; LIMA, J. L. Estabilidade de produção de híbridos simples e duplos de milho oriundos de um mesmo conjunto gênico. Bragantia, Campinas, v. 67, p. 627-631, 2008. DOI: $10.1590 / \mathrm{S} 0006-87052008000300010$.

MAGAlhães, P. C.; DURÃES, F. O. M. Fisiologia da produção de milho. Sete Lagoas: Embrapa Milho e Sorgo, 2006. 10 p. (Embrapa Milho e Sorgo. Circular Técnica, 76). 
SANTOS, H. G. dos; JACOMINE, P. K. T.; ANJOS, L. H. C. dos; OLIVEIRA, V. A. de; LUMBRERAS, J. F.; COELHO, M. R.; ALMEIDA, J. A. de; CUNHA, T. J. F.; OLIVEIRA, J. B. de. Sistema brasileiro de classificação de solos. 3. ed. rev. e ampl. Brasília, DF: Embrapa, 2013. $353 \mathrm{p}$.

SHIOGA, P.; GERAGE, A. C. Influência da época de plantio no desempenho do milho safrinha no estado do Paraná, Brasil. Revista Brasileira de Milho e Sorgo, Sete Lagoas, v. 9, n. 3, p. 236-253, 2010.

DOI: 10.18512/1980-6477/rbms.v9n3p236-253.

SILVA, A. G.; TEIXEIRA, I. R.; MARTINS, P. D. S.; SIMON, G. A.; FRANCISCHINI, R. Desempenho agronômico e econômico de híbridos de milho na safrinha. Revista Agro@mbiente On-line, Boa Vista, v. 8, n. 2, p. 261-271, 2014.

DOI: 10.18227/1982-8470ragro.v8i2.1706.

SILVA, M. A. V.; FERREIRA, W. P. M.; ANDRADA, V. M. S.; ARAÚJO, S. G. A. Época de semeadura do milho para a região de Sete Lagoas, $\mathrm{MG}$, baseada na probabilidade de ocorrência de períodos secos e chuvosos. Revista Ceres, Viçosa, MG, v. 57, n. 4, p. 454-459, 2010.

DOI: 10.1590/S0034-737X2010000400003.

STRINGFIEL, G. H. Heterozygosis and hybrid vigor in maize. Agronomy Journal, Madison, v. 42, p. 145-152, 1950.

THORNTHWAITE, C. W.; MATHER, J. R. The water balance. New Jersey: Drexel institute of technology, 1955. 104 p. (Climatology, v. 8, n. 1).

VAZ-DE-MELO, A.; AFFÉRRI, F. S.; DOTTO, M. A.; PELUZIO, J. M.; RODRIGUES, G. R. S.; CARVALHO, E. V. D. Reação de híbridos de milho à Curvularia ssp, sob dois níveis de adubação com nitrogênio, no sul do Tocantins. Scientia Agraria, Curitiba, v. 11, n. 2, p. 149154,2010

WHEATHERSPOON, J. H. Comparative yields of single, three-way, and double crosses of maize. Crop Science, Madison, v. 10, n. 2, p. 157-159, 1970.

DOI: 10.2135/cropsci1970.0011183X001000020011x. 